\title{
Definition of Stress and Strain Ranges for Multiaxial Fatigue Life Evaluation under Non-Proportional Loading
}

\author{
by \\ Takamoto Iтон ${ }^{*}$, Masao SAKANE ${ }^{* *}$ and Yuuta Shimizu ${ }^{* * *}$
}

\begin{abstract}
A simple and clear method of evaluating stress and strain ranges under non-proportional multiaxial loading where principal directions of stress and strain are changed during a cycle is needed for assessing multiaxial fatigue. This paper proposes a simple method of determining the principal stress and strain ranges and the severity of non-proportional loading with defining the rotation angles of the maximum principal stress and strain in a three dimensional stress and strain space. Based on the method proposed, non-proportional stress and strain ranges are derived and applicability of the range to the life evaluation of type 304 stainless steel under 15 proportional and non-proportional strain paths are discussed. The strain range taking account of intensity of loading path reducing life can be suitable parameter for multiaxial fatigue life evaluation under non-proportional loading.
\end{abstract}

Key words : Multiaxial fatigue, Non-proportional loading, Stress and strain, Fatigue life evaluation, Low cycle fatigue

\section{Introduction}

Most design codes use equivalent values to express the intensity of multiaxial stress or strain, like von Mises or Tresca equivalent stress and strain, and fatigue lives are usually estimated using equivalent values under multiaxial stress and strain states. The equivalent value means a scalar parameter that expresses intensity of a physical phenomenon in multiaxial stress states and should be reduced to be a uniaxial value in uniaxial stress state. Most widely used equivalent parameters are the von Mises and the Tresca equivalent stresses and strains. The von Mises equivalent stress physically expresses the intensity of shear strain energy and the Tresca equivalent stress that of the maximum shear stress. For example, ASME Section III, Division $1 \mathrm{NH}^{1)}$ uses the von Mises equivalent strain and ASME Section VIII, Division $3^{2)}$ the maximum shear stress.

However, the von Mises equivalent stress and strain have no negative values so that they have a difficulty of expressing stress and strain ranges. The Tresca equivalent stress and strain have negative values but they also have a difficulty to put a sign to the shear stress and strain under multiaxial loading. Especially, in non-proportional loading where the principal stress and strain change their directions, giving a sign to them becomes more difficult. A simple and clear method of calculating stress and strain ranges is needed for describing multiaxial fatigue.

Low cycle fatigue (LCF) lives are reduced under strain controlled non-proportional loading accompanied by additional cyclic hardening compared with proportional loading $^{3) \sim 8)}$ and an appropriate design method of evaluating the non-proportional fatigue life is needed for a reliable design and maintenance of structural components. Classical models particularly applicable in multiaxial fatigue life evaluation under proportional loadings lead to overestimate the lives under non-proportional loadings. For life evaluation under non-proportional loading, commonly proposed models are critical plane approaches that consider specific plane applied the critical damage, such as a Simith-Watoson-Topper ${ }^{9)}$ and a Fatemi-Socie ${ }^{10}$ models. The authors also proposed a strain parameter (Itoh-Sakane model) estimating the non-proportional LCF lives for several materials under various strain histories. ${ }^{6,7)}$, 11) 15) This parameter is the strain based model with introducing two parameters, non-proportional factor and material constant. The former one reflects the intensity of non-proportional loading reducing life and the latter one is related to the material dependence for degree of life reduction due to non-proportional loading.

The Simith-Watoson-Topper, the Fatemi-Socie and the Itoh-Sakane models have been demonstrated to be applicable to life evaluation under non-proportional loading using hollow cylinder specimens in a laboratory level. That is, these models can be applicable to the life evaluation under limited non-proportional loadings such as the loadings in the plane stress state. However, many components and structures such as turbine blade, pressure vessel and pipe which receive combined thermal and mechanical loadings undergo non-proportional loading in which principal directions of stress and strain are changed into

$\dagger \quad$ Received June 18, 2012 @ 2013 The Society of Materials Science, Japan

* $\quad$ Member : Div. of Mech. Eng., Graduate School of Engineering, Univ. of Fukui, Bunkyo, Fukui, 910-8507 Japan

* * Member : Dept. of Mech. Eng., Collage of Science \& Engineering, Ritsumeikan Univ., Nojihigashi, Kusatsu, 525-8577 Japan

*** Graduate Student, Course of Mech. Eng., Graduate School of Engineering, Univ. of Fukui, Bunkyo, Fukui, 910-8507 Japan 
various directions under wider multiaxial stress and strain states. ${ }^{8), 13), 16) ~ 18)}$ Therefore, a development of suitable models for the design of actual components where variation in principal directions of stress and strain vs time is changed 3-dimensionally is required.

This study proposes a method of evaluating the principal stress and strain ranges and the mean stress and strain, and also proposes a method of calculating the nonproportional factor which expresses the severity of nonproportional loading in 3-dimantional (3D) stress and strain space. Based on the method proposed, non-proportional strain and stress ranges are derived and applicability of the range to the life evaluation of type 304 stainless steel under 15 proportional and non-proportional strain paths are also discussed.

\section{Stress and Strain Ranges under Non-proportional Loading}

\subsection{Definition of Stress and Strain}

Fig. 1 illustrates three principal vectors, $\boldsymbol{S}_{\mathrm{i}}(t)$, applied to a small cube in material at time $t$ in $x y z$-coordinates (spatial coordinates), where " $S$ " is the symbol denoting either stress " $\sigma$ " or strain " $\varepsilon$ ". Thus, $\boldsymbol{S}_{\mathrm{i}}(t)$ are the principal stress vectors for the case of stress and are the principal strain vectors for the case of strain. The subscript, i, takes 1,2 or 3 in descending order of principal stress or strain. The maximum principal vector, $\boldsymbol{S}_{\mathrm{I}}(t)$, is defined as $\boldsymbol{S}_{\mathrm{i}}(t)$ whose absolute value takes maximum one, i.e., $\boldsymbol{S}_{\mathrm{I}}(t)=\boldsymbol{S}_{1}(t)$ when $\boldsymbol{S}_{1}(t)$ takes maximum magnitude among $\boldsymbol{S}_{\mathrm{i}}(t)$. The maximum principal value, $\boldsymbol{S}_{\mathrm{I}}(t)$, is defined as the maximum absolute value of $\boldsymbol{S}_{\mathrm{i}}(t)$ as,

$$
S_{\mathrm{I}}(t)=\left|\boldsymbol{S}_{\mathrm{I}}(t)\right|=\operatorname{Max}\left[\left|\boldsymbol{S}_{1}(t)\right|,\left|\boldsymbol{S}_{2}(t)\right|,\left|\boldsymbol{S}_{3}(t)\right|\right]
$$

The "Max" denotes taking the larger value from the three in the bracket. The maximum value of $\boldsymbol{S}_{\mathrm{I}}(t)$ during a cycle is defined as the maximum principal value, $S_{\text {Imax }}$, at $t=t_{0}$ as follows,

$$
S_{\text {Imax }}=\left|\boldsymbol{S}_{\mathrm{I}}\left(t_{0}\right)\right|=\operatorname{Max}\left[\left|\boldsymbol{S}_{1}\left(t_{0}\right)\right|,\left|\boldsymbol{S}_{2}\left(t_{0}\right)\right|,\left|\boldsymbol{S}_{3}\left(t_{0}\right)\right|\right]
$$

\subsection{Definition of Principal Stress and Strain Directions}

Fig. 2 illustrates two angles, $\xi(t) / 2$ and $\zeta(t)$, to express the rotation or direction change of the maximum principal vector, $\boldsymbol{S}_{\mathrm{I}}(t)$, in the new coordinate system of $X Y Z$,

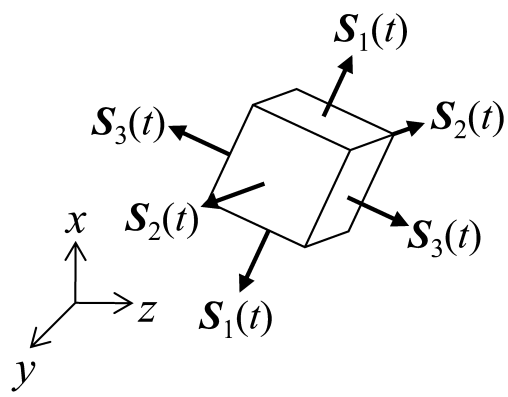

Fig. 1 Principal strees and strain in $x y z$ coordinates.
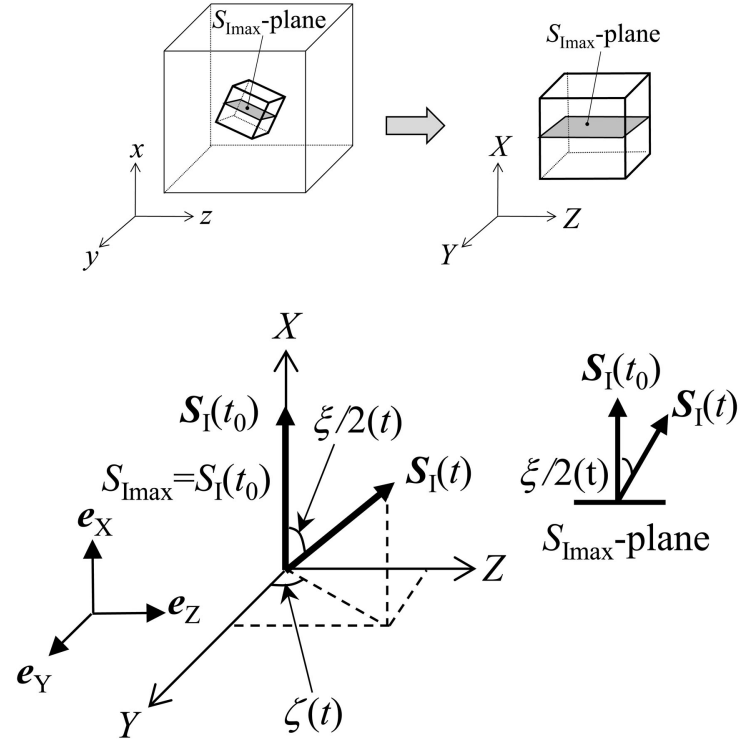

Fig. 2 Definition of principal stress and strain directions in $X Y Z$ coordinates.

where $X Y Z$-coordinates are the material coordinates taking $X$-axis in the direction of $\boldsymbol{S}_{\mathrm{I}}\left(t_{0}\right)$ with the other two axes in arbitrary directions. The two angles of $\xi(t) / 2$ and $\zeta(t)$ are given by

$$
\begin{aligned}
& \frac{\xi(t)}{2}=\cos ^{-1}\left(\frac{\boldsymbol{S}_{\mathrm{i}}\left(t_{0}\right) \cdot \boldsymbol{S}_{\mathrm{i}}(t)}{\left|\boldsymbol{S}_{\mathrm{i}}\left(t_{0}\right)\right|\left|\boldsymbol{S}_{\mathrm{i}}(t)\right|}\right) \quad\left(0 \leq \frac{\xi(t)}{2} \leq \frac{\pi}{2}\right) \\
& \zeta(t)=\tan ^{-1}\left(\frac{\boldsymbol{S}_{\mathrm{i}}(t) \cdot \boldsymbol{e}_{\mathrm{Z}}}{\boldsymbol{S}_{\mathrm{i}}(t) \cdot \boldsymbol{e}_{\mathrm{Y}}}\right) \quad(0 \leq \zeta(t) \leq 2 \pi)
\end{aligned}
$$

where dots in Eqs (3) and (4) denote the inner product and $\boldsymbol{e}_{\mathrm{Y}}$ and $\boldsymbol{e}_{\mathrm{Z}}$ are unit vectors in $Y$ and $Z$ directions, respectively. $\boldsymbol{S}_{\mathrm{i}}(t)$ are the principal vectors of stress or strain used in Eq. (1) and the subscript i takes 1 or 3.

The rotation angle of $\xi(t) / 2$ expresses the angle between the $\boldsymbol{S}_{\mathrm{I}}\left(t_{0}\right)$ and $\boldsymbol{S}_{\mathrm{I}}(t)$ directions and the deviation angle of $\zeta(t)$ is the angle of $\boldsymbol{S}_{\mathrm{I}}(t)$ direction from the $Y$-axis in the $X$-plane.

\subsection{Definitions of Stress and Strain in Polar Figure}

Fig. 3 shows the trajectory of $\boldsymbol{S}_{\mathrm{I}}(t)$ in 3D polar figure for a cycle where the radius is taken as the value of $\boldsymbol{S}_{\mathrm{I}}(t)$, and the angles of $\xi(t)$ and $\zeta(t)$ are the angles shown in 
the figure. A new coordinate system is used in Fig. 3 with the three axes of $\mathrm{S}_{\mathrm{I}}^{1}, \mathrm{~S}_{\mathrm{I}}^{2}$ and $\mathrm{S}_{\mathrm{I}}^{3}$, where $\mathrm{S}_{\mathrm{I}}^{1}$-axis directs to the direction of $\boldsymbol{S}_{\mathrm{I}}\left(t_{0}\right)$. The rotation angle of $\xi(t)$ has double magnitude compared with that in the specimen shown in Fig. 2 considering the consistency of the angle between the polar figure and the physical plane presentation. The principal range, $\Delta \boldsymbol{S}_{\mathrm{I}}$, is determined as the maximum projection length of $\boldsymbol{S}_{\mathrm{I}}(t)$ on the $\mathrm{S}_{\mathrm{I}}{ }^{1}$-axis. The mean value, $S_{\text {Imean }}$, is given as the center of the range. $\Delta S_{\text {I }}$ and $S_{\text {Imean }}$ are equated as,

$$
\begin{aligned}
& \Delta S_{\mathrm{I}}=\operatorname{Max}\left[S_{I_{\max }}-\cos \xi(t) S_{\mathrm{I}}(t)\right]=S_{I_{\max }}-S_{I_{\text {min }}} \\
& S_{I_{\text {mean }}}=\frac{1}{2}\left(S_{I_{\text {max }}}+S_{I_{\text {min }}}\right)
\end{aligned}
$$

$S_{\text {Imin }}$ is the $\boldsymbol{S}_{\text {I }}(t)$ to maximize the value of the bracket in Eq. (5). The sign of $S_{\text {Imin }}$ in the figure is set to be positive if it does not cross the $\mathrm{S}_{I}^{2}-\mathrm{S}_{I}{ }^{3}$ plane and the sign negative if it crosses the plane.

The advantage of the definitions of the maximum principal range and mean value above mentioned is that the two are determinable without human judgments for any loading case in 3D stress and strain space. The range and mean value are consistent used in simple loading cases which are discussed in the case studies in the followings. $\boldsymbol{S}_{\text {I }}(t)$ can be replaced by equivalent values of stress or strains, such as the von Mises and the Tresca, in case of necessity from user's requirement.

\section{Case Studies}

This section discusses a couple of case studies for $\Delta S_{\mathrm{I}}$ and $S_{\text {Imean }}$ under proportional and non-proportional loadings under biaxial plane stress condition. The symbol $S$ takes strain $(\varepsilon)$ in the case studies in the followings.

\section{1 Proportional Loading}

Fig. 4 (a) illustrates three proportional strain paths for normal and shear strainings under plane stress condition in the normal strain - shear strain $(\varepsilon-\gamma / \sqrt{3})$ plot. The path A-A' is push-pull loading, the B-B' combined tension and shear loading and the path C-C' shear loading. Figs 4 (b)-(d) show the variations of $\varepsilon_{1}(t), \varepsilon_{3}(t), \varepsilon_{\mathrm{I}}(t), \xi(t) / 2$ and $\zeta(t)$ and Fig. $4(\mathrm{e})$ the strain path in the polar figure presentation.

Principal strains and their angle change are obtained in the stages of OA-OB-OC and OA'-OB'-OC' as follows.

Stage OA-OB-OC :

$$
\begin{aligned}
& \left.\begin{array}{l}
\varepsilon_{1}(t) \\
\varepsilon_{2}(t)=\varepsilon_{3}(t)
\end{array}\right\}=\frac{1-v}{2} \varepsilon \pm \frac{1}{2} \sqrt{(1+v)^{2} \varepsilon^{2}+\gamma^{2}} \\
& \varepsilon_{\mathrm{I}}(t)=\varepsilon_{1}(t) \quad \text { Since of } \varepsilon_{1}(t) \geq\left|\varepsilon_{3}(t)\right| \\
& \varepsilon_{\mathrm{I} \max }=\varepsilon_{\mathrm{I}}(k) \quad k=\mathrm{A}, \mathrm{B} \text { or } \mathrm{C} \\
& \xi(t)=0^{\circ}, \quad \zeta(t)=0^{\circ}
\end{aligned}
$$

$$
\begin{aligned}
& \text { Stage OA'-OB'-OC' : } \\
& \left.\begin{array}{l}
\varepsilon_{1}(t)=\varepsilon_{2}(t) \\
\varepsilon_{3}(t)
\end{array}\right\}=\frac{1-v}{2} \varepsilon \pm \frac{1}{2} \sqrt{(1+v)^{2} \varepsilon^{2}+\gamma^{2}} \\
& \varepsilon_{\mathrm{I}}(t)=\left|\varepsilon_{3}(t)\right| \quad \text { Since of } \varepsilon_{1}(t) \leq\left|\varepsilon_{3}(t)\right| \\
& \xi(t)=180^{\circ}, \quad \zeta(t)=0^{\circ}
\end{aligned}
$$

$v$ is the Poisson's ratio. Note that $\gamma / \sqrt{3}=0$ in the loading stages of $\mathrm{OA}$ and $\mathrm{OA}^{\prime}$ and $\varepsilon=0$ in the loading stages of $\mathrm{OC}$ and $\mathrm{OC}$ '.

The maximum principal strains $\left(\varepsilon_{1}(t)\right)$ vary along the solid lines in Fig. 4 (b) in the loading stages of OA, OB and $\mathrm{OC}$, and the minimum principal strains $\left(\varepsilon_{3}(t)\right)$ along the dashed lines in the same loading stages. In these cases, the maximum principal strains all have a positive sign, whereas

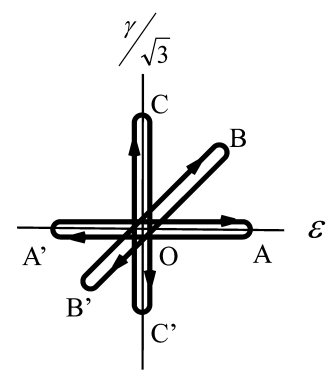

(a) Strain paths on $\varepsilon-\gamma / \sqrt{3}$ plot

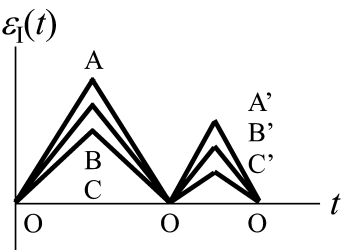

(c) Variation of $\varepsilon_{1}(t)$

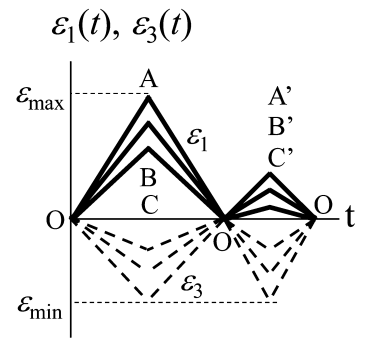

(b) Variation of $\varepsilon_{i}(t)$

$$
\xi(t) / 2, \zeta(t)
$$

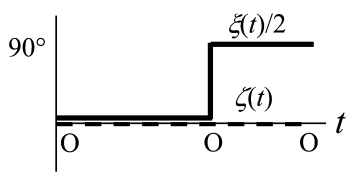

(d) Variation of $\xi(t)$ and $\zeta(t)$

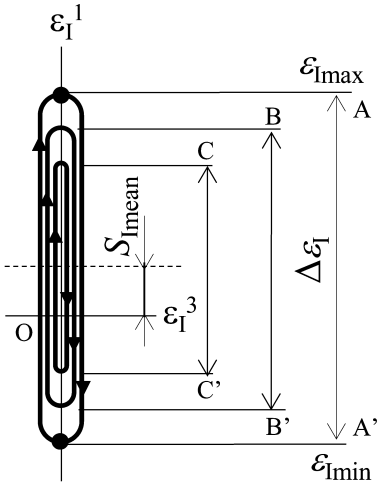

(e) Strain paths on polar figure

Fig. 4 Variations of $\varepsilon_{1}(t), \varepsilon_{\mathrm{I}}(t)$ and $\xi(t) / 2$ in proportional straining: (a) Strain paths on $\varepsilon-\gamma / \sqrt{3}$ plot, (b) Variation of $\varepsilon_{\mathrm{I}}(t)$, (c) Variation of $\varepsilon_{\mathrm{I}}(t)$, (d) Variation of $\xi(t)$ and $\zeta(t)$, (e) Strain paths on polar figure. 
the minimum principal strains a negative sign. $\varepsilon_{\mathrm{I}}(t)$ makes the positive triangle waveforms as illustrated in Fig. 4 (c) because $\varepsilon_{\mathrm{I}}(t)$ is either $\varepsilon_{1}(t)$ or $\varepsilon_{3}(t)$ taking larger absolute strain as shown in Eq. (1). The principal strain, $\varepsilon_{\mathrm{I}}(t)$, changes its direction by an angle of $180^{\circ}\left(\xi / 2=90^{\circ}\right)$ at the origin $\mathrm{O}$ in the reversed loading stages of $\mathrm{AA}^{\prime}, \mathrm{BB}^{\prime}$ and CC', Fig. 4 (d). Finally, the straight loading lines are obtained in the polar figure as shown in Fig. 4 (e). In the proportional loadings in Fig. 4 (a), the directions of $\varepsilon_{\mathrm{I}}(t)$ are fixed $\left(\xi=0\right.$ or $\left.180^{\circ}\right)$ and $\zeta=0^{\circ}$.

The maximum strain range and mean strain are expressed as

$$
\begin{aligned}
& \Delta \varepsilon_{\mathrm{I}}=\varepsilon_{\text {Imax }}+\varepsilon_{\text {Imin }}=\varepsilon_{1}(k)-\varepsilon_{3}\left(k^{\prime}\right) \\
& \varepsilon_{\text {Imean }}=\frac{1}{2}\left(\varepsilon_{\text {Imax }}-\varepsilon_{\text {Imin }}\right)=\frac{1}{2}\left(\varepsilon_{1}(k)+\varepsilon_{3}\left(k^{\prime}\right)\right)
\end{aligned}
$$

as shown in Fig. 4 (e), where $k$ takes A, B or C and $k$ ' A', B' and C'. The results agree well with the principal strain range and mean strain we have considered by putting a sign with human operation.

\subsection{Non-proportional Loading}

Fig. 5 shows non-proportional loading cases of the cruciform and box shapes. In the figure, $\varepsilon_{\operatorname{Imax}}$ is assumed to be given by $\varepsilon_{\mathrm{I}}(\mathrm{A})$ and $\varepsilon_{\mathrm{I}}(\mathrm{a})$ in the cruciform and box shape loadings, respectively. The principal strains and the direction of $\varepsilon_{\mathrm{I}}(t)$ in each stage in the figure are expressed as follows.

Principal strains :

Stage OA, OB, OD and DdAaB

$$
\begin{aligned}
& \left.\begin{array}{l}
\varepsilon_{1}(t) \\
\varepsilon_{2}(t)=\varepsilon_{3}(t)
\end{array}\right\}=\frac{1-v}{2} \varepsilon \pm \frac{1}{2} \sqrt{(1+v)^{2} \varepsilon^{2}+\gamma^{2}} \\
& \varepsilon_{\mathrm{I}}(t)=\varepsilon_{1}(t) \quad \text { Since of } \varepsilon_{1}(t) \geq\left|\varepsilon_{3}(t)\right| \\
& \varepsilon_{\mathrm{I} \max }=\varepsilon_{\mathrm{I}}(\mathrm{A})=\varepsilon_{1}(\mathrm{~A}) \quad \text { for cruciform loading } \\
& \varepsilon_{\mathrm{I} \max }=\varepsilon_{\mathrm{I}}(\mathrm{a})=\varepsilon_{1}(\mathrm{a}) \quad \text { for box }- \text { shaped loading }
\end{aligned}
$$

\section{Stage $\mathrm{OC}$ and $\mathrm{BbCcD}$}

$$
\begin{aligned}
& \left.\begin{array}{l}
\varepsilon_{1}(t) \\
\varepsilon_{2}(t)=\varepsilon_{3}(t)
\end{array}\right\}=\frac{1-v}{2} \varepsilon \pm \frac{1}{2} \sqrt{(1+v)^{2} \varepsilon^{2}+\gamma^{2}} \\
& \varepsilon_{\mathrm{I}}(t)=\left|\varepsilon_{3}(t)\right| \quad \text { Since of } \varepsilon_{1}(t) \leq\left|\varepsilon_{3}(t)\right|
\end{aligned}
$$

Direction of $\varepsilon_{\mathrm{I}}(t)$ :

Stage OA, OB, OD for cruciform loading

$$
\begin{aligned}
& \xi(t)=0^{\circ}, \zeta(t)=0^{\circ} \text { along OA } \\
& \xi(t)=90^{\circ}, \zeta(t)=90^{\circ} \text { along OB } \\
& \xi(t)=90^{\circ}, \zeta(t)=-90^{\circ} \text { along OD }
\end{aligned}
$$

Stage OC for cruciform loading

$\xi(t)=180^{\circ}, \zeta(t)=0^{\circ}$ along OC

Stage aBbCc for box-shaped loading

$0 \leq \xi(t) \leq 180^{\circ}, \zeta(t)=90^{\circ}$

Stage cDdAa for box-shaped loading

$$
0 \leq \xi(t) \leq 180^{\circ}, \zeta(t)=-90^{\circ}
$$

In the cruciform loading, $\varepsilon_{\mathrm{I}}(t)$ makes four triangles shown in Figs $5(\mathrm{~b})$ and (c). The angle of $\xi(t)$ rotates in the range of $0 \leq \xi(t) \leq 180^{\circ}$, Fig. $5(\mathrm{~d})$, and the angle of $\zeta(t)$ changes by $90^{\circ}$ at the origin $\mathrm{O}$ in a cycle. The principal strain path in the polar figure became a cruciform shape as shown in Fig. 5 (e).

In the box loading, $\varepsilon_{1}(t)$ takes positive and $\varepsilon_{3}(t)$ negative values without changing sign in a cycle as shown in Fig. 5 (b). Then, $\varepsilon_{\mathrm{I}}(t)$ in the box loading has large mean value with a small fluctuation during a cycle, Fig. 5 (c). The principal strain direction rotates continually in the range of $0 \leq \xi(t) \leq 180^{\circ}$ and $\zeta(t)= \pm 90^{\circ}$ and the principal strain path forms rhombus shape, Figs 5 (d) and (e).

The maximum strain ranges are

$$
\begin{array}{rlr}
\Delta \varepsilon_{\mathrm{I}} & =\varepsilon_{\text {Imax }}+\varepsilon_{\text {Imin }} & \text { for cruciform loading } \\
& =\varepsilon_{1}(\mathrm{~A})-\varepsilon_{3}(\mathrm{C}) & \\
\Delta \varepsilon_{\mathrm{I}} & =\varepsilon_{\text {I } \max }+\varepsilon_{\text {Imin }} & \text { for box-shaped loading } \\
& =\varepsilon_{1}(\mathrm{a})-\varepsilon_{3}(\mathrm{c}) &
\end{array}
$$

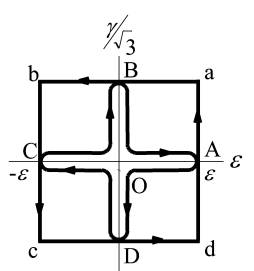

(a) Strain paths on $\varepsilon-\gamma / \sqrt{3}$ plot

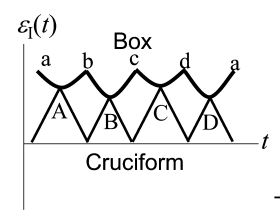

(c) Variation of $\varepsilon_{\mathrm{l}}(t)$

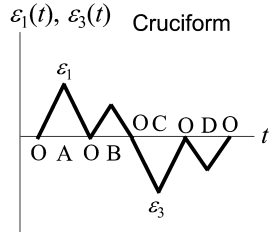

(b) Variation of $\varepsilon_{\mathrm{i}}(t)$
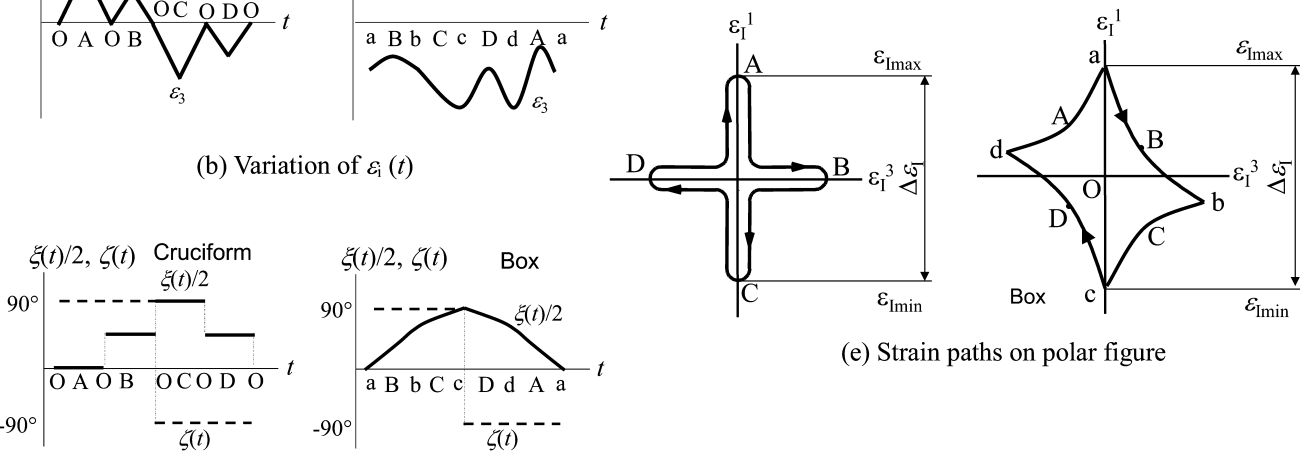

(e) Strain paths on polar figure

Fig. 5 Variations of $\varepsilon_{\mathrm{i}}(t), \varepsilon_{\mathrm{I}}(t)$ and $\xi(t) / 2$ in nonproportional straining : (a) Strain paths on $\varepsilon-\gamma / \sqrt{3}$ plot, (b) Variation of $\varepsilon_{\mathrm{I}}(t)$, (c) Variation of $\varepsilon_{\mathrm{I}}(t)$, (d) Variation of $\xi(t)$ and $\zeta(t)$, (e) Strain paths on polar figure. 


\section{Definition of Non-proportionality}

The authors proposed the non-proportional strain range expressed in Eq. (13) for correlating LCF lives under non-proportional loading. ${ }^{6), 7), 11) \sim 14)}$

$$
\Delta \varepsilon_{\mathrm{NP}}=\left(1+\alpha f_{\mathrm{NP}}\right) \Delta \varepsilon_{\mathrm{I}}
$$

In the equation, $\Delta \varepsilon_{\mathrm{I}}$ is the principal strain range discussed previously. $\alpha$ is a material constant expressing the amount of additional hardening by non-proportional loading and is defined as the ratio of a saturated principal stress in the circular loading to that in uniaxial push-pull loading at the same principal strain amplitude for additional hardening material. In Eq. (13), $\Delta \varepsilon_{\text {I }}$ also can be replaced by the other equivalent stains based on the user's requirement although trends of data correlation are different between the strains used which have been discussed in other studies. ${ }^{8), 19) ~ ~ 21) ~}$

$f_{\mathrm{NP}}$ is the non-proportional factor that expresses the severity of non-proportional loading in the form as, ${ }^{6), 7), 11) ~ ~ 14) ~}$

$$
f_{\mathrm{NP}}=\frac{b}{\mathrm{~T} \varepsilon_{\mathrm{I} \max }} \int_{0}^{T}\left(|\sin (\xi(t))| \varepsilon_{\mathrm{I}}(t)\right) \mathrm{d} t
$$

where $T$ is the time for a cycle. $b$ is a constant for making $f_{\mathrm{NP}}=1$ in the circular loading on $\varepsilon-\gamma / \sqrt{3}$ plot and $b$ takes $\pi / 2$ when $\varepsilon_{\mathrm{I}}(t)$ is employed. ${ }^{6), 7)}$ In Eq. (14), $f_{\mathrm{NP}}$ is calculated by measuring the rotation of the maximum principal strain direction and the integration the strain amplitude after the rotation. Therefore, $f_{\mathrm{NP}}$ evaluates comprehensively the severity of non-proportional cyclic loading based on the amplitude of strain and the direction change of principal strain.

This paper proposes a modified non-proportional factor, $f^{\prime}{ }_{\mathrm{NP}}$, to be applicable for 3D stress and strain space defined in chapter 3 , which is expressed as,

$$
\begin{gathered}
f_{\mathrm{NP}}^{\prime}=\frac{\pi}{2 S_{\text {Imax }} L_{\text {path }}} \int_{C}\left|\boldsymbol{e}_{1} \times \boldsymbol{e}_{\mathrm{R}}\right| S_{\mathrm{I}}(t) \mathrm{d} s \\
L_{\text {path }}=\int_{C} \mathrm{~d} s
\end{gathered}
$$

where $\boldsymbol{e}_{\mathrm{R}}$ is a unit vector directing to $\boldsymbol{S}_{\mathrm{I}}(t)$, ds the infinitesimal trajectory of the loading path shown in Fig. 3. $L_{\text {path }}$ is the whole loading path length during a cycle and “×” denotes vector product. The scalars, $S_{\mathrm{Imax}}$ and $L_{\mathrm{path}}$, before the integration in Eq. (15) is set to make $f^{\prime}{ }_{\mathrm{NP}}$ unity in the circler loading in 3D polar figure. Integrating the product of amplitude and principal direction change of stress and strain by path length in Eq. (15) is more suitable for evaluation of fatigue damage rather than the integration by time.

Fig. 6 compares the values of $f_{\mathrm{NP}}$ with those of $f^{\prime}{ }_{\mathrm{NP}}$ for several loading paths for the case of strain. Small difference in the value between $f_{\mathrm{NP}}$ and $f^{\prime}{ }_{\mathrm{NP}}$ is found because of different definition between them. However, $f^{\prime}{ }_{\mathrm{NP}}$ has the advantages applicable to 3D stress and strain conditions.

Fig. 7 shows a flow chart of calculation of stress or strain range and non-proportionality. When 6 components of stress or strain at time $t$ as the data obtained from experiment, numerical analysis such as a finite element analysis or etc., $\Delta S_{\text {I }}$ and $f^{\prime}{ }_{N P}$ are calculated based on the procedures presented in above. Then, evaluation of fatigue damage can be analyzed by user's method or Itoh-Sakane model. ${ }^{13)}$

\section{Non-proportional Stress and Strain Ranges for Life Evaluation}

The authors analyzed the non-proportional LCF lives of type 304 steel tube specimens fatigued using 15 strain waveforms shown in Fig. 8 at $923 \mathrm{~K}^{22)}$ Figs 9 (a)-(c) correlate non-proportional fatigue lives with the ASME equivalent strain range $\left(\Delta \varepsilon_{\mathrm{ASME}}\right)$ and two maximum stress ranges of $\Delta \sigma_{\mathrm{I}}^{\mathrm{e}}$ and $\Delta \sigma_{\mathrm{I}} . \Delta \varepsilon_{\mathrm{ASME}}$ is the strain range based on Mises equivalent strain and is the strain range recommended in the Code Case of ASME, Section III, Division $1 \mathrm{NH}^{1)} \Delta \sigma_{\mathrm{I}}^{\mathrm{e}}$ is the principal stress range calculated from $\Delta \varepsilon_{\mathrm{I}}$ multiplied by Young's modulus of $145 \mathrm{GPa}$. The correla-

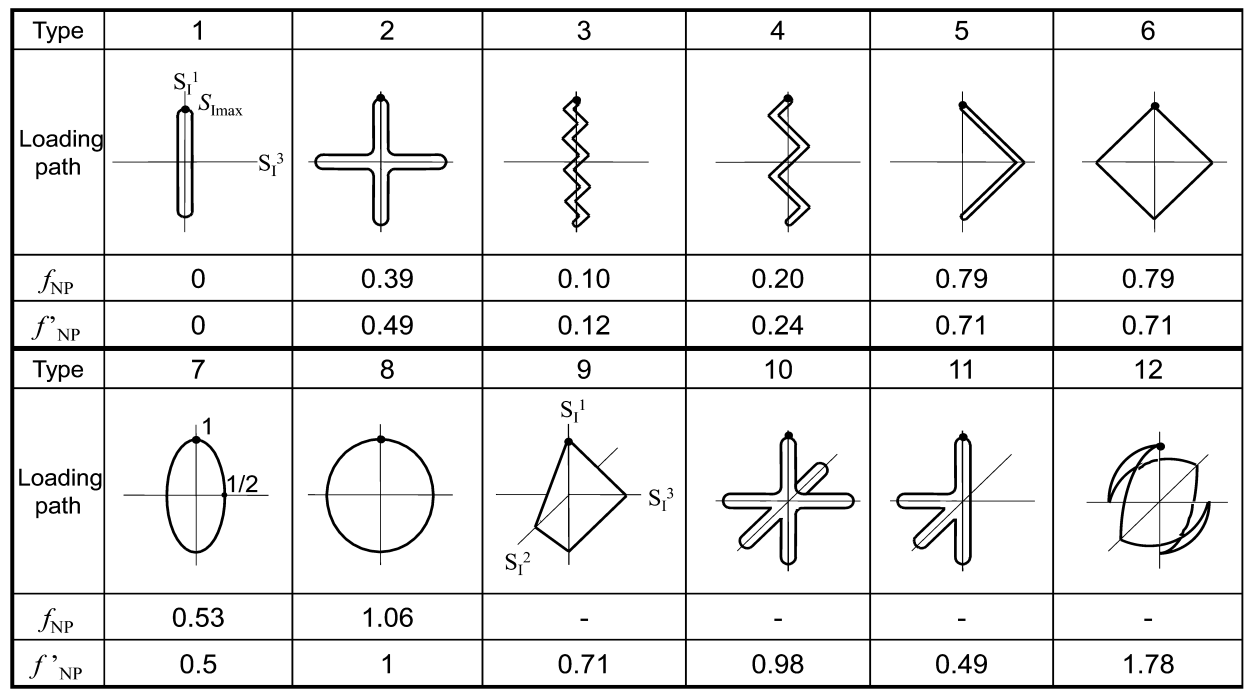

Fig. 6 Comparing $f_{\mathrm{NP}}$ and $f^{\prime}{ }_{\mathrm{NP}}$ under several loadings. 


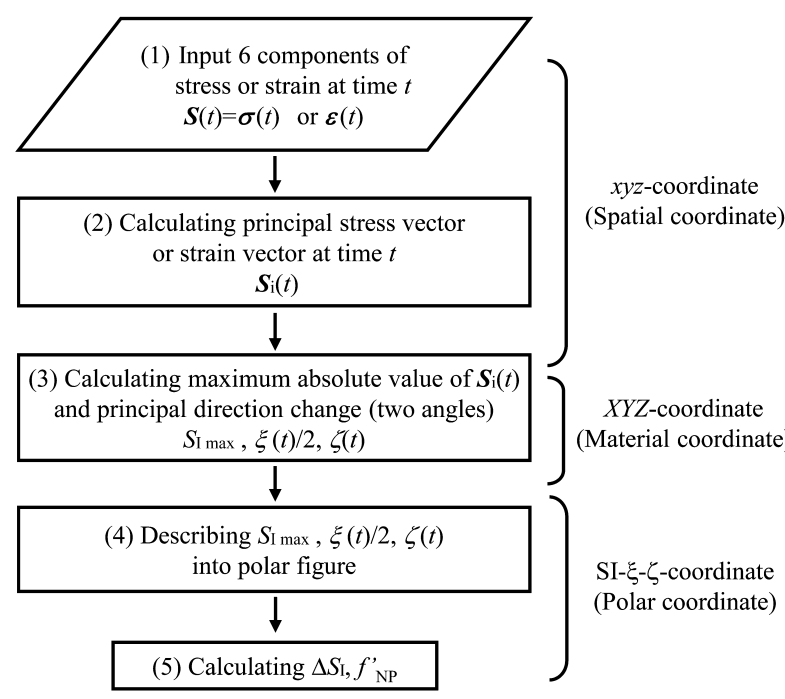

Fig. 7 Flow chart of calculation of stress or strain range and non-proportionality.
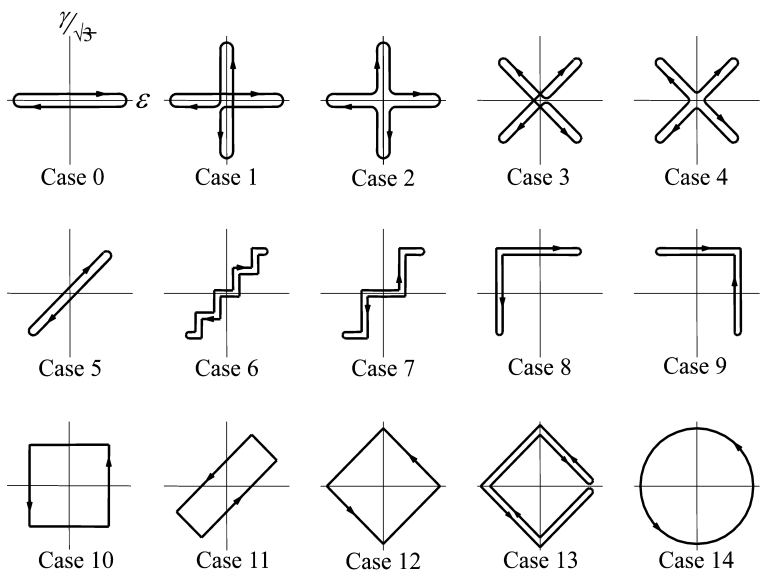

Fig. 815 strain paths employed in the non-proportional LCF test.

tion using $\Delta \sigma_{\mathrm{I}}^{\mathrm{e}}$ was made considering that conventional design usually uses stress ranges elastically calculated from strain ranges. $\Delta \sigma_{\mathrm{I}}$ is the maximum principal stress range experimentally obtained at $1 / 2 N_{\mathrm{f}}$. In the figures, heavy solid lines are drawn based on the Case 0 data and two thin solid lines show a factor of 2 scatter band.

Fig. 9 (a) clearly indicates that $\Delta \varepsilon_{\mathrm{ASME}}$ overestimates the non-proportional fatigue lives in the cases with sever non-proportionalities. For type 304 stainless steel at room temperature, the more drastic reduction in LCF lives due to non-proportional loading beyond a factor of 10 was also reported. ${ }^{4)}$ 5), 7), 12), 15) The cause of the overestimates results from that $\Delta \varepsilon_{\mathrm{ASME}}$ does not cover the effect of nonproportional loading on life. The correlation with $\Delta \sigma_{\mathrm{I}}^{\mathrm{e}}$ shown in Fig. 9 (b) appears to be a similar trend to that in Fig. 9 (a). $\Delta \sigma_{\mathrm{I}}^{\mathrm{e}}$ has larger magnitude than experimental practically because the stress was calculated elastically even in plastic deformation occurred. In the data correlation with $\Delta \sigma_{\mathrm{I}}$, Fig. 9 (c), LCF lives under non-proportional

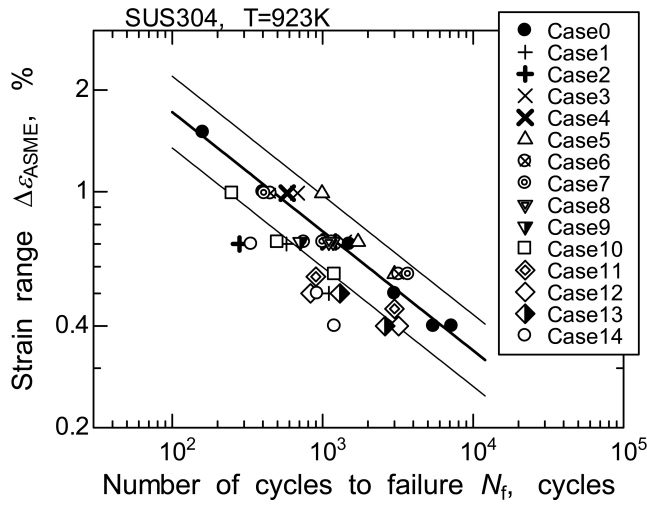

(a) $\Delta \varepsilon_{\mathrm{ASME}}-N_{\mathrm{f}}$

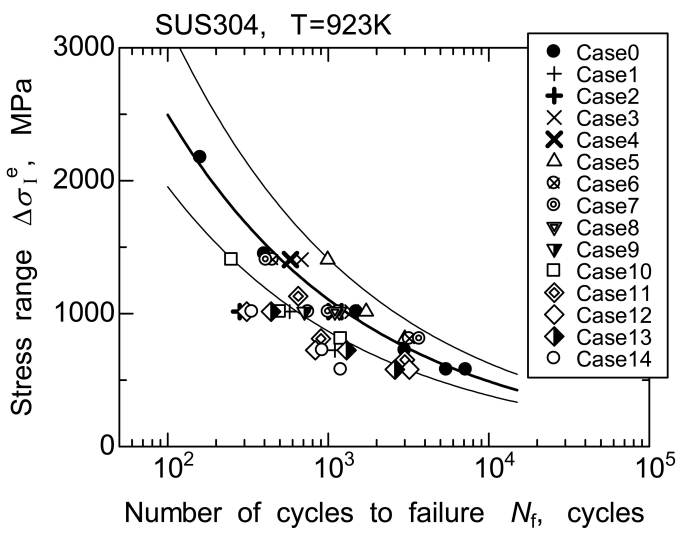

(b) $\Delta \sigma_{\mathrm{I}}^{c}-N_{\mathrm{f}}$

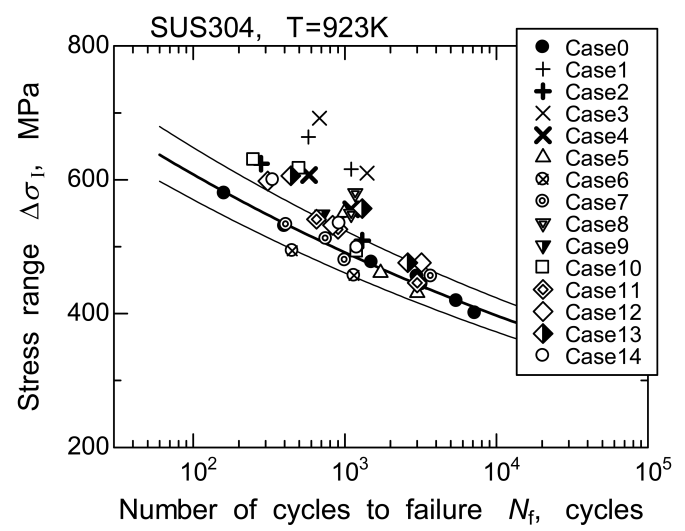

(c) $\Delta \sigma_{\mathrm{I}}-N_{\mathrm{f}}$

Fig. 9 Correlation of non-proportional LCF lives with $\Delta \varepsilon_{\mathrm{ASME}}$, $\Delta \sigma_{\mathrm{I}}^{\mathrm{e}}$ and $\Delta \sigma_{\mathrm{I}}$ : (a) $\Delta \varepsilon_{\mathrm{ASME}}-N_{\mathrm{f}}$, (b) $\Delta \sigma_{\mathrm{I}}^{\mathrm{e}}-N_{\mathrm{f}}$, (c) $\Delta \sigma_{\mathrm{I}}-N_{\mathrm{f}}$.

loading are underestimated. The underestimate of the LCF lives under non-proportional loading may result from the additional hardening due to non-proportional loading, because $\Delta \sigma_{\text {I }}$ does not cover the additional hardening due to non-proportional loading resulting in reduction in life.

Fig. 10 correlates the non-proportional LCF lives with $\Delta \varepsilon_{\mathrm{NP}}$, where material constant, $\alpha$, is set to $0.4 . \Delta \varepsilon_{\mathrm{NP}}$ correlates the non-proportional fatigue lives with a small scatter. $\alpha$ employed was determined from the degree of additional hardening. This result suggests that a suitable 


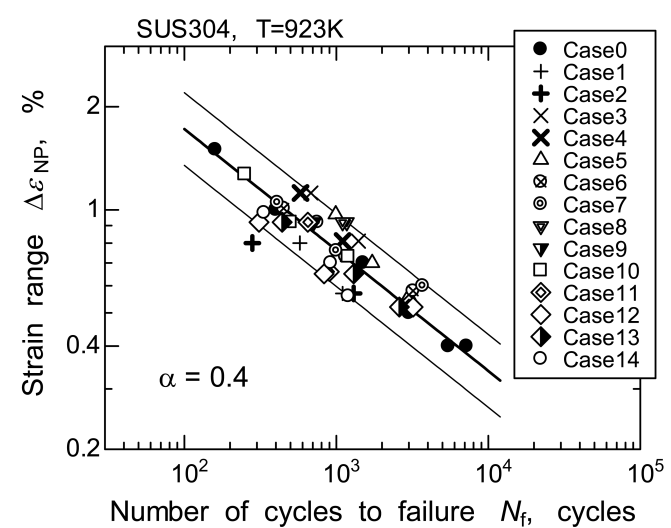

Fig. 10 Correlation of non-proportional LCF lives with $\Delta \varepsilon_{\text {NPP. }}$.

strain parameter for multiaxial LCF life evaluation must take account of intensity of non-proportionality of loading and additional hardening due to non-proportional loading. The former is the non-proportional factor, $f_{\mathrm{NP}}$ or $f^{\prime} \mathrm{NP}$, and the latter is the material constant, $\alpha$, in $\Delta \varepsilon_{\mathrm{NP}}$.

\section{Conclusions}

(1) This paper proposed a simple method of determining the principal stress and strain ranges together with the mean stress and strain under proportional and nonproportional loading in 3D stress and strain space. It also proposed the method of defining the rotation and deviation angles of the maximum principal stress and strain.

(2) The paper extend the non-proportional factor, $f_{\mathrm{NP}}$, from $2 \mathrm{D}$ to $3 \mathrm{D}$ stress and strain space with the consistency with the previous definition of it in the $2 \mathrm{D}$ space.

(3) Applicability of the non-proportional strain was discussed for describing the high temperature proportional and non-proportional low cycle fatigue lives.

\section{References}

1) ASME, Boiler and Pressure Vessel Code Section III, Division 1 NH (2004).

2) ASME, Boiler and Pressure Vessel Code Section VIII, Division 3 (2004).

3 ) A. Fatemi and D. F. Socie, "A critical plane approach to multiaxial fatigue damage including out-of-phase loading”, Fatigue and Fracture of Engineering Materials and Structures, Vol.11, No.3, pp.149-165 (1988).

4 ) A. Nitta, T. Ogata and K. Kuwabara, "Fracture modes and fatigue life evaluation of SUS 304 stainless steel under non-proportional biaxial loading conditions", Journal of the Society of Materials Science, Japan, Vol.38, No.427, pp.416-422 (1989).

5 ) S. H. Doong, D. F. Socie and I. M. Robertson, "Dislocation substructures and nonproportional hardening", Transaction of the American Society of Mechanical Engineers, Journal of Engineering Materials and Technology, Vol.112, pp.456-565 (1990).
6) T. Itoh, M. Sakane, M. Ohnami and D. F. Socie, "Nonproportional low cycle fatigue criterion for type 304 stainless steel", Transaction of the American Society of Mechanical Engineers, Journal of Engineering Materials and Technology, Vol.117, pp.285-292 (1995).

7 ) T. Itoh, T. Nakata, M. Sakane and M. Ohnami, "Non-proportional low cycle fatigue of 6061 aluminum alloy under 14 strain path”, Multiaxial Fatigue and Fracture (Eds : E. Macha, W. Bedowski \& T. Lagoda), ESIS-25, pp.41-54 (1999).

8 ) D. F. Socie, G. Marquis and G, eds, "Multiaxial fatigue", SAE International (2000).

9) R. N. Smith, P. Watson and T. H. Topper, "A stress-strain parameter for the fatigue of metals", Journal of Materials, Vol.5, No.4, pp.767-778 (1970).

10) N. Shamsaei, A. Fatemi and D. F. Socie, "Multiaxial fatigue evaluation using discriminating strain paths", International Journal of Fatigue, Vol.33, No.4, pp.597-609 (2011).

11) Itoh $T$, "Effect of direction change in maximum principal strain axis on multiaxial low cycle fatigue life of type 304 stainless steel at elevated temperature”, Journal of the Society of Materials Science, Japan, Vol.49, No.9, pp.988-993 (2000).

12) T. Itoh, "A model for evaluation of low cycle fatigue lives under non-proportional straining”, Journal of the Society of Materials Science, Japan, Vol.50, No.12, pp.1317-1322 (2001).

13) T. Itoh, M. Sakane, T. Hata and N. Hamada, "A design procedure for assessing low cycle fatigue life under proportional and non-proportional loading”, International Journal of Fatigue, Vol.28, No.8, pp.495-466 (2006).

14) T. Itoh, M. Sakane and T. Ozaki, "Determination of strain and stress ranges under cyclic proportional and non-proportional loading”, Journal of the Society of Materials Science, Japan, Vol.60, No.2, pp.88-93 (2011).

15) T. Itoh and T. Yang, "Material dependence of multiaxial low cycle fatigue lives under non-proportional loading", International Journal of Fatigue, Vol.33, No.8, pp.1025-1031 (2011).

16) T. Ogata and A. Nitta, "Evaluation of multiaxial low-cycle fatigue failure based on new criterion and its application to high temperature structural design”, Journal of the Society of Materials Science, Japan, Vol.42, No.472, pp.72-77 (1993).

17) M. Kobayashi, N. Ohno and T. Igari, "Thermal ratcheting analysis of cylinders subjected to axial travelling of temperature distribution: comparison with experiments of 316FR steel cylinders", Journal of the Society of Materials Science, Japan, Vol.46, No.8, pp.906-913 (1997).

18) K. Aoto, "Structural materials development for sodium cooled fast reactor”, Materia Japan, Vol.47, No.9, pp.459-463 (2008).

19) M. Sakane, M. Ohnami and M. Sawada, "Fracture modes and low cycle biaxial fatigue life at elevated temperature", Transaction of the American Society of Mechanical Engineers, 
Journal of Engineering Materials and Technology, Vol.109, pp.236-242 (1987).

20) M. Sakane, M. Ohnami and N. Hamada, "Biaxial low cycle fatigue for notched, cracked, and smooth specimens at high temperature", Transaction of the American Society of Mechanical Engineers, Journal of Engineering Materials and Technology, Vol.110, pp.48-54 (1988).

21) T. Itoh, M. Sakane and M. Ohnami, "High temperature multiaxial low cycle fatigue of cruciform specimen", Transaction of the American Society of Mechanical Engineers, Journal of Engineering Materials and Technology, Vol.116, pp.90-98 (1994).

22) N. Hamada and M. Sakane, "High temperature nonproportional low cycle fatigue using fifteen loading paths", Proceedings of the 5th International Conference on Biaxial/Multiaxial Fatigue and Fracture, Vol.1, pp.251-266 (1997).

\section{Appendix}

\section{Derivation of $f^{\prime}{ }_{\mathrm{NP}}$ from $f_{\mathrm{NP}}$}

The original non-proportional factor is expressed as,

$$
f_{\mathrm{NP}}=\frac{b}{\mathrm{~T} \varepsilon_{\mathrm{I} \max }} \int_{0}^{T}\left(|\sin (\xi(t))| \varepsilon_{\mathrm{I}}(t)\right) \mathrm{d} t
$$

where $T$ is the time for a cycle. $b$ is a constant for making $f_{\mathrm{NP}}=1$ in the circular loading on $\varepsilon-\gamma / \sqrt{3}$ plot and $b=\pi / 2$.

In the modified non-proportional factor, $f^{\prime}{ }_{\mathrm{NP}}, \varepsilon_{\mathrm{I}}(t)$ is replaced by $S_{\mathrm{I}}(t)$ to be applied into $3 \mathrm{D}$ stress and strain space defined in this study. The product of amplitude and principal direction change of stress and strain is integrated by path length ( $\mathrm{d} s$ ) which may become more suitable for evaluation of fatigue damage rather than $f^{\prime}$ NP integrated by time $(\mathrm{d} t)$

The $f^{\prime}{ }_{\mathrm{NP}}$ is expressed as,.

$$
\begin{gathered}
f_{\mathrm{NP}}^{\prime}=\frac{\pi}{2 S_{\text {Imax }} L_{\text {path }}} \int_{C}\left|\boldsymbol{e}_{1} \times \boldsymbol{e}_{\mathrm{R}}\right| S_{\mathrm{I}}(t) \mathrm{d} s \\
L_{\text {path }}=\int_{C} \mathrm{~d} s
\end{gathered}
$$

where " $\times$ " denotes vector product and $\boldsymbol{e}_{1} \times \boldsymbol{e}_{\mathrm{R}}=\sin (\xi(t))$. $L_{\text {path }}$ is the whole loading path length during a cycle. The scalars, $S_{\text {Imax }}$ and $L_{\text {path }}$, is set to make $f^{\prime}{ }_{N P}$ unity in the circler loading in 3D polar figure. 